\title{
Sistem Pakar Mendiagnosa Penyakit Epilepsi Menggunakan Metode Dempster Shafer
}

\author{
Faisal Anggi Mahesa ${ }^{1}$, Sulindawaty ${ }^{2}$ \\ ${ }^{1,2}$ STMIK Pelita Nusantara \\ Program Studi Teknik Informatika STMIK Pelita Nusantara \\ J1. ST. Iskandar Muda No.1 Medan, Indonesia \\ Corresponding author‘s e-mail: icalmahal28@gmail.com
}

\begin{abstract}
Abstrak - Perkembangan ilmu pengetahuan di era revolusi industri 4.0 ini sangatlah pesat. Hal ini terlihat pada terciptanya berbagai teknologi yang dapat membantu pekerjaan banyak pihak. Tidak dapat dipungkiri teknologi dibidang komputer sangat amat dibutuhkan oleh berbagai instansi pemerintah dan swasta di Indonesia disegala bidang terutama dibidang kesehatan yang dapat digunakan dalam membantu dalam mendiagnosa penyakit seperti epilepsi. Epilepsei dapat menyerang, baik itu pria maupun wanita, anak-anak maupun orang dewasa. Pada umumnya, semua orang memiliki sel epilepsi yang akan terhubung ke otak manusia. Hal ini terlihat pada terciptanya berbagai teknologi yang dapat membantu pekerjaan banyak pihak Salah satu dibidang komputer yang dapat membantu dalam mendiagnosa penyakit epilepsi dengan menggunakan Ilmu Sistem Pakar (Expert System). Penelitian ini menggunakan metode Dempster Shafer. Penelitian ini menggunakan 3 jenis penyakit epilepsi yaitu Epilepsi Umum, Epilepsi Parsial, dan Epilepsi Sekunder dan menggunakan 13 gejala. Dari hasil penelitian ini didapatkan bahwa diagnosa paling akurat adalah Epilepsi Umum dengan tingkat kepercayaan 99\% dan berdasarkan gejala yang terpilih maka diagnosa paling akurat adalah Parsial Primer, Parsial Sekunder dengan tingkat kepercayaan $74 \%$.
\end{abstract}

Kata Kunci : Sistem Pakar, Epilepsi, Rumah Sakit, Akurat.

Abstract- The development of science in the era of the industrial revolution 4.0 is very fast. This can be seen in the creation of various technologies that can help the work of many parties. It is undeniable that technology in the field of computers is very much needed by various government and private agencies in Indonesia in all fields, especially in the health sector which can be used to assist in diagnosing diseases such as epilepsy. Epilepsei can strike, both men and women, children and adults. Basically everyone can have epilepsy because everyone has a brain the seizure threshold of each is more resistant or less resistant to the appearance of seizures One field computer that can assist in the diagnosis of epilepsy using Expert System Sciences ( Expert System ). This study uses the Dempster Shafer method. This study uses 3 types of epilepsy, namely General Epilepsy, Partial Epilepsy, and Secondary Epilepsy and uses 13 symptoms. From the results of this study, it was found that the most accurate diagnosis was General Epilepsy with a confidence level of 99\% and based on the selected symptoms, the most accurate diagnosis was Partial Primary, Partial Secondary with a confidence level of $74 \%$.

Keywords: Expert System, Epilepsy, Hospital, Accurate.

\section{Pendahuluan}

Perkembangan ilmu pengetahuan di era revolusi industri 4.0 ini sangatlah pesat. Hal ini terlihat pada terciptanya berbagai teknologi yang dapat membantu pekerjaan banyak pihak. Tidak dapat dipungkiri teknologi dibidang komputer sangat amat dibutuhkan oleh berbagai instansi pemerintah dan swasta di Indonesia disegala bidang terutama dibidang kesehatan yang dapat digunakan dalam membantu dalam mendiagnosa penyakit. Epilepsi adalah salah satu penyakit yang dapat menyerang siapapun, baik itu pria maupun wanita, anak-anak maupun orang dewasa. Pada dasarnya semua orang dapat mengalami epilepsi karena setiap orang memiliki otak dengan ambang bangkitan masing-masing apakah lebih tahan atau kurang tahan terhadap munculnya bangkitan[1]. Ambang bangkitan atau Kejang (epileptic) adalah manifestasi klinis disebabkan oleh lepasnya muatan listrik secara sinkron dan berlebihan dari sekelompok neuron di otak yang bersifat transien[2]. Salah satu dibidang komputer yang dapat membantu dalam mendiagnosa penyakit epilepsi adalah Ilmu Sistem Pakar (Expert System).

Kurangnya pengetahuan akan penyakit ini dan ditambah lagi ketidaktahuan akan adanya gejala pada orang yang terkena epilepsi dapat mambuat lambatnya penanganan dan pengobatan pada orang tersebut. Maka dari itu dibuatlah sistem pakar untuk membantu memberikan penanganan pada orang yang terkena epilepsi dengan cepat. Sistem Pakar merupakan sistem yang menggunakan pengetahuan dalam mengumpulkan fakta agar dapat dilakukan penalaran sebuah masalah yang biasanya hanya bisa dilakukan oleh pakar dibidangnya. Dan disaat 
sekarang ini sistem pakar telah banyak digunakan dalam bidang kesehatan untuk mengetahui atau mendiagnosa berbagai jenis penyakit.

Sistem pakar pada penelitian ini menggunakan metode Dempster Shafer untuk mendiagnosis penyakit epilepsi. Metode Dempster Shafer pertama kali diperkenalkan oleh Arthur P. Dempster, yang melakukan percobaan model ketidakpastian dengan rangeprobabilities sebagai probabilitas tunggal. Kemudian pada tahun 1976 Glenn Shafer mempublikasikan teori Dempster tersebut pada sebuah buku yang berjudul Mathematical Theory Of Evident[3]. Dempster Shafer adalah teori matematika yang digunakan untuk pembuktian berdasarkan belief functions dan plausible reasoning (fungsi kepercayaan dan pemikiran yang masuk akal), yang digunakan untuk mengkombinasikan potongan informasi yang terpisah (bukti) untuk mengkalkulasi kemungkinan dari suatu peristiwa[4].

Berdasarkan dari penelitian yang dilakukan oleh Junaidi dan Agustin dengan judul "Diagnosa Jenis Penyakit Epilepsi pada Anak Menggunakan Metode Certainty Factor"[5]. Hasil implementasi yang telah dilakukan, aplikasi sistem pakar menggunakan metode certainty factor dapat menganalisis gejala-gejala jenis penyakit epilepsi berdasarkan gejala yang diberikan oleh pasien menjadi sebuah keputusan jenis penyakit epilepsi. Sehingga aplikasi ini dapat memberikan kemudahan bagi dokter dalam melakukan diagnosa penyakit epilepsi pada anak dengan cepat, mudah dan efektif. Penelitian yang dilakukan oleh Nicolina Djiu, dan Syaiful Rahman, dan Izmy Alwiah Musdar dengan judul "Penerapan Metode Hill Climbing Untuk Mendiagnosa Penyakit Gangguan Saraf Berbasis Android". Hasil dari implementasi ini, sistem dengan menerapkan metode Hill Climbing untuk mendiagnosa penyakit gangguan saraf menunjukkan bahwa metode ini mampu memberikan hasil diagnosa sementara berupa informasi awal mengenai kemungkinan penyakit yang diderita oleh pengguna tersebut. Oleh karena itu, Penelitian ini dirasa perlu dilakukan untuk membantu dalam mendiagnosa penyakit epilepsi pada pasien dengan menggunakan sistem yang terkomputerisasi.

\section{Tinjauan Pustaka}

\subsection{Konsep Sistem Pakar}

Dalam pembuatan tugas ahir penulis membutuhkan teori-teori yang dapat mendukung kemudahan dalam mempelajari maupun merancang program aplikasi yang diharapkan dapat digunakan dan berfungsi secara optimal. Penulis berharap dengan adanya program yang dibuat, para pengguna (user) lebih mudah dalam melakukan pekerjaannya, sehingga dapat membantu dalam menyelesaikan masalahdengan baik dan dapat memperkecil terjdinya suatu kesalahan yang dilakukan oleh pengguna.

Sistem pakar disusun oleh dua bagian utama yaitu lingkungan pengenbangan (development environment) dan lingkungan konsultasi (consultation environment)[6]. Lingkungan pengembangan sistem pakar digunakan untuk memasukan pengetahuan pakar kedalam lingkungan sistem pakar, sedangkan lingkungan konsultasi digunakan oleh pengguna yang bukan pakar dalam memperoleh pengetahuan pakar.

\subsection{Pengertian Pakar}

Pakar adalah orang yang memiliki kemampuan atau keahlian khusus untuk menyelesaikan suatu masalah yang tidak dapat diselesaikan oleh orang awam[7]. Sebagai contoh, dokter adalah seorang pakar yang mampu mendiagnosis penyakityang diderita pasien serta dapat memberikan penatalaksanaan terhadap penyakit tersebut.

\subsection{Sistem Pakar}

Sistem pakar adalah suatu program komputer yang dirancang untuk mengambil keputusan seperti keputusan yang diambil oleh seorang atau beberapa orang pakar. Sistem pakar adalah sistem perangkat lunak komputer yang menggunakan ilmu, fakta, dan teknik berpikir dalam pengambilan keputusan untuk menyelesaikan masalah-masalah yang biasanya hanya dapat diselesaikan oleh tenaga ahli dalam bidang yang bersangkutan[8].

Sistem pakar memungkinkan seseorang yang memahami suatu permasalahan terbantu melalui aplikasi sistem pakar yang dibuat. Permasalahan telah diidentifikasidapat dipeoses dan diolah sedemikian rupa sehingga dihasilkan suatu kesimpulan mengenai suatu permasalahan[9].

\subsection{Dempster Shafer}

Dempster shafer adalah suatu teori matematika untuk pembuktian belief functions and plausible reasoning (Fungsi kepercayaan dan pemikiran yang masuk akal), yang digunakan mengkombinasikan potongan informasi yang terpisah (bukti) untuk mengkalkulasi kemungkinan dari suatu peristiwa. Teori ini dikembangkan oleh Arthur P.Dempster dan Glen Shafer. Teori Dempster Shafer merupakan salah satu metode yag mampu mengakomodasi ketidak pastian dalam klasifikasi multispectral. Teori ini digunakan untuk mengkombinasikan potongan informasi yang terpisah untuk mengkalkulasikan kemungkinan dari suatu peristiwa. 


\subsection{Epilepsi}

Penyakit epilepsi adalah penyakit gangguan sistem saraf pusat akibat pola aktivitas listrik otak yang tidak normal. Ha itu menimbulkan keluhan kejang, sensasi dan prilaku yang tidak biasa, hingga hilang kesadaran. Gangguan pada pola aktivitas listrik otak saraf dapat terjadi karena beberapa hal. Baik karena kelainan pada jaringan otak, ketidakseimbangan zat kimia di dalam otak, ataupun kombinasi dari beberapa faktor penyebab tersebut. Epilepsi adalah salah satu penyakit yang dapat menyerang siapapun, baik itu pria maupun wanita, anak-anak maupun orang dewasa. Pada dasarnya semua orang dapat mengalami epilepsi karena setiap orang memiliki otak dengan ambang bangkitan masing- masing apakah lebih tahan atau kurang tahan terhadap munculnya bangkitan.

\subsection{PHP}

PHP adalah bahasa scripting server-side, bahasa pemrograman yang digunakan untuk mengembangkan situs web statis atau situs web dinamis dan aplikasi web. Script sendiri merupakan sekumpulan instruksi pemrograman yang ditafsirkan pada saat runtime[10]. Sedangkan Bahasa scripting adalah bahasa yang menafsirkan skrip saat runtime. Dan biasanya tertanam ke dalam lingkungan perangkat lunak lain. PHP adalah bahasa pemrograman umum yang berarti php dapat disematkan ke dalam kode HTML, atau dapat digunakan dalam kombinasi dengan berbagai sistem templat web, sistem manajemen konten web, dan kerangka kerja web.

\subsection{XAMPP}

XAMPP adalah sebuah paket perangkat lunak (software) komputer yang sistem penamaannya diambil dari akronim kata Apache, MySQL (dulu) / MariaDB (sekarang), PHP, dan Perl. Program aplikasi XAMPP berfungsi sebagai server lokal untuk mengampu berbagai jenis data website yang sedang dalam proses pengembangan. Dalam prakteknya, XAMPP bisa digunakan untuk menguji kinerja fitur ataupun menampilkan konten yang ada didalam website kepada orang lain tanpa harus terkoneksi dengan internet, cukup akses melalui Xampp control panel, atau istilahnya website offline. XAMPP bekerja secara offline layaknya web hosting biasa namun tidak bisa diakses oleh banyak orang. Maka dari itu, XAMPP biasanya banyak digunakan oleh para mahasiswa maupun pelajar untuk melihat hasil desain website sebelum akhirnya dibuat online menggunakan web hosting yang biasa dijual dipasaran[11].

\section{Metode Penelitian}

Bagian ini menggambarkan bagaimana kerangka penelitian yang dilakukan agar sesuai dengan tujuan dan hasil yang diinginkan dengan waktu yang efisien. Adapun kerangka penelitian dapat dilihat pada gambar berikut: 


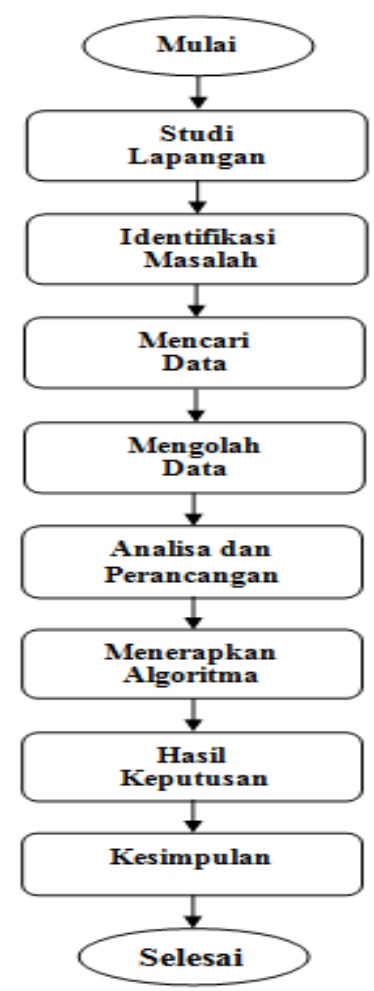

Gambar 1. Kerangka Kerja Penelitian.

\section{Hasil dan Pembahasan}

Langkah-langkah penyelesaiannya:

\subsection{Analisa Data}

Tahapan analisa terhadap suatu sistem merupakan tahapan awal yang akan dibangun sebelum tahapan perancangan dilakukan. Teknik pengumpulan data yang akan dilakukan para peneliti yaitu menggunakan teknik pengamatan (observasi) dan wawancara secara langsung kepada pihak Doter Spesialis Syaraf pada tempat penelitian. Untuk mendiagnosa penyakit Epilepsi di RSUD Sultan Sulaiman

Adapun data-data yang akan dikumpulkan adalah sebagai berikut :

1. Data Penyakit

2. Data Gejala

3. Cara Pencegahan dan Pengobatan penyakit yang di derita.

4. Data Pasien

\subsection{Tempat Penelitian}

Pelaksanaan penelitian yang dibahas dalam membangun sebuah aplikasi ini yaitu Sistem Pakar Mendiagnosa Penyakit Epilepsi dilakukan di RSUD Sultan Sulaiman yang beralamat di Jl. Negara KM.58, Firdaus, Kab. Sedang Brdagai, Prov. Sumatra Utara

Gambaran umum sistem yang sedang berjalan :

1. Pasien datang langsung kebagian pendaftaran.

2. Pasien mengambil nomor antrian.

3. Pasien menunggu nomor antrian untuk dipanggil.

4. Bagian administrasi memanggil pasien untuk melakukan pendaftaran.

5. Pasien menyerahkan berkas

6. Pasien mendaftar dengan menyerahkan identitas diri untuk mendapatkan nomor rekam medis.

7. Pasien mendapatkan nomor urut kartu untuk diperiksa

8. Menunggu dipanggil di depan ruang dokter sesuai tujuan.

9. Pasien masuk keruang dokter untuk konsultasi atau berobat.

10. Dokter menulis hasil periksa dari pasien

11. Dokter memberikan catatan hasil periksa ke bagian obat.

12. Bagian obat membuat resep obat sesuai anjuran dari dokter.

\subsection{Algoritma Metode Epilepsi}


Algoritma sistem pakar ini menerangkan sekaligus menggambarkan sebuah proses bagaimana cara mengaplikasikan sistem pakar diagnosa penyakit epilepsi menggunakan metode Dempster Shafer ini agar dapat berjalan dengan baik. Flowchart adalah gambaran suatu bentuk diagram alir dari algoritma-algoritma yang menyatakan arah alur program ke dalam suatu program. Flowchart dapat menunjukkan dengan jelas gambaran suatu alur secara logis dan sistematis serta menunjukkan berbagai kegiatan secara menyeluruh untuk menentukan suatu penyakit.

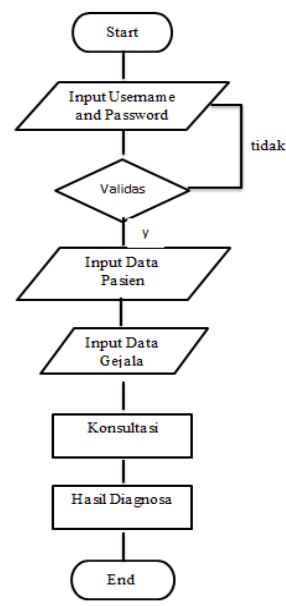

Gambar 2. Flowchart Algoritma Sistem

Pada tahapan analisis metode dempster shafer ini dapat menunjukkan suatu cara untuk memberikan bobot pada keyakinan sesuai fakta yang dikumpulkan. Metode dempster shafer ini sangat cocok digunakan dalam penelitian ini karena teori ini dapat membedakan ketidakpastian dan ketidaktahuan [12]. Sehingga metode ini memiliki nilai densitas dan tingkat kepastian yang tinggi dalam mendiagnosa sebuah penyakit.

Langkah-langkah dalam membuat sistem pakar menggunakan metode dempster shafer yaitu :

1. Menentukan nilai hipotesa dari gejala-gejala penyakit epilepsi.

2. Menyusun gejala-gejala tersebut kedalam sistem

3. Menghitung atau menentukan frame of discernment yang dinotasikan dengan $\theta$.

4. Menghitung nilai tertinggi atau nilai kepercayaan yang didapat dari setiap gejala-gejala penyakit dengan metode dempster shafer.

5. Hasil akhir berupa persentase yang dijadikan sebagai nilai kepercayaan dari setiap pertanyaan yang dijawab oleh user, dan kemudian hasil itu menentukan bahwa orang tersebut menderita penyakit epilepsi.

\section{Identifikasi Jenis Penyakit dan Gejala}

Berikut ini adalah daftar jenis dari penyakit epilepsi dan keterangan penyakit tersebut :

Tabel 1 Jenis-jenis Penyakit Epilesi

\begin{tabular}{|c|c|}
\hline Kode Penyakit & Nama Penyakit \\
\hline P01 & Epilepsi Umum \\
\hline P02 & Epilepsi Parsial \\
\hline P03 & Epilepsi Sekunder \\
\hline
\end{tabular}

\section{Gejala Penyakit Epilepsi}

Berikut adalah Gejala dari penyakit epilepsi yang dialami oleh penderita penyakit epilepsi :

Tabel 2 Gejala Penyakit Epilesi

\begin{tabular}{|c|c|c|c|}
\hline No & Kode Gejala & Nama Gejala & Bobot \\
\hline 1. & A1 & Hilang kesadaran & 0.8 \\
\hline 2. & A2 & Kontraksi otot dikepala & 0.4 \\
\hline 3. & A3 & Kejang toknik klonik & 0.6 \\
\hline 4. & A4 & Keluar busa dari mulut & 0.8 \\
\hline 5. & A5 & Mengeluarkan urine & 0.1 \\
\hline 6. & A6 & Mengorok & 0.6 \\
\hline 7. & A7 & Keterbelakangan mental & 0.4 \\
\hline
\end{tabular}




\begin{tabular}{|l|c|c|c|}
\hline 8. & A8 & Melempar benda & 0.8 \\
\hline 9. & A9 & Rasa Kesemutan & 0.1 \\
\hline 10. & A10 & Daya ingat terganggu & 0.4 \\
\hline 11. & A11 & Timbulnya halusinasi & 0.6 \\
\hline 12. & A12 & Berlari-lari tanpa tujuan & 0.8 \\
\hline 13. & A13 & Faktor keturunan & 0.4 \\
\hline
\end{tabular}

Dari tabel dapat dilihat gejala-gejala dari penyakit epilepsi maka setelah itu penulis memasukan bobot atau terminologi kepastian dari suatu gejala yang ada, table terminologi dapat dilihat pada table di bawah :

Tabel 3 Nilai Persentase Dempster Shafer
\begin{tabular}{|c|c|c|}
\hline No & Keterangan & Nilai \\
\hline 1 & Tidak tahu & $0 \%-19 \%$ \\
\hline 2 & Sedikit Yakin & $20 \%-39 \%$ \\
\hline 3 & Cukup Yakin & $40 \%-69 \%$ \\
\hline 4 & Yakin & $70 \%-89 \%$ \\
\hline 5 & Sangat Yakin & $90 \%-100 \%$ \\
\hline
\end{tabular}

\section{Penentuan If Then}

Tabel 4 Gejala Penyakit Epilepsi Beserta Nilai Belief

\begin{tabular}{|c|c|c|c|}
\hline Kode Penyakit & Nama Penyakit & Gejala & Bobot \\
\hline \multirow{8}{*}{$\mathrm{P} 1$} & \multirow{8}{*}{ Epilepsi Umum } & 1. Hilang kesadaran & 0.8 \\
\hline & & 2. Kontraksi otot dikepala & 0.4 \\
\hline & & 3. Kejang toknik klonik & 0.6 \\
\hline & & 4. Keluar busa dari mulut & 0.8 \\
\hline & & 5. Mengeluarkan urine & 0.1 \\
\hline & & 6. Mengorok & 0.6 \\
\hline & & 7. Keterbelakangan mental & 0.4 \\
\hline & & 8. Melempar benda & 0.8 \\
\hline \multirow{5}{*}{$\mathrm{P} 2$} & \multirow{5}{*}{ Parsial Primer } & 1. Rasa Kesemutan & 0.1 \\
\hline & & 2. Daya ingat terganggu & 0.4 \\
\hline & & 3. Timbulnya halusinasi & 0.6 \\
\hline & & 4. Berlari-lari tanpa tujuan & 0.8 \\
\hline & & 5. Faktor keturunan & 0.4 \\
\hline \multirow{6}{*}{$\mathrm{P} 3$} & \multirow{6}{*}{$\begin{array}{c}\text { Parsial } \\
\text { Sekunder }\end{array}$} & 1. Hilang kesadaran & 0.8 \\
\hline & & 2. Kontraksi otot dikepala & 0.4 \\
\hline & & 3. Kejang toknik klonik & 0.6 \\
\hline & & 4. Rasa Kesemutan & 0.1 \\
\hline & & 5. Daya ingat terganggu & 0.4 \\
\hline & & 6. Timbulnya halusinasi & 0.6 \\
\hline
\end{tabular}

\section{Studi Kasus Perhitungan Gejala Penyakit Secara Acak}

Tabel 5 Gejala Penyakit yang dipilih acak

\begin{tabular}{|c|c|c|c|}
\hline No & Kode Gejala & Nama Gejala & Bobot \\
\hline 1. & A5 & Mengeluarkan urine & 0.1 \\
\hline 2. & A10 & Daya ingat terganggu & 0.4 \\
\hline 3. & A11 & Timbulnya halusinasi & 0.6 \\
\hline
\end{tabular}

Tabel 6 Perhitungan

\begin{tabular}{|c|c|c|}
\hline \multicolumn{3}{|c|}{ Daya Ingat Terganggu (P2, P3) } \\
\hline$\#$ & $\mathrm{P} 2, \mathrm{P} 3 » 0.4$ & $\emptyset » 0.6$ \\
\hline $\mathrm{P} 1, \mathrm{P} 2, \mathrm{P} 3 » 1$ & $\mathrm{P} 2, \mathrm{P} 3 » 0.4$ & $\mathrm{P} 1, \mathrm{P} 2, \mathrm{P} 3 » 0.6$ \\
\hline Kombinasi Diagnosa & Rumus & Nilai \\
\hline $\mathrm{P} 1, \mathrm{P} 3$ & $(0.4) /(1-[])$ & 0.4 \\
\hline $\mathrm{P} 1, \mathrm{P} 2, \mathrm{P} 3$ & $(0.6) /(1-[])$ & 0.6 \\
\hline
\end{tabular}


Tabel 7 Perhitungan

\begin{tabular}{|c|c|c|}
\hline \multicolumn{3}{|c|}{ Timbulnya Halusinasi (P2, P3) } \\
\hline$\#$ & $\mathrm{P} 2, \mathrm{P} 3 » 0.6$ & $\emptyset » 0.4$ \\
\hline $\mathrm{P} 2, \mathrm{P} 3 » 0.4$ & $\mathrm{P} 2, \mathrm{P} 3 » 0.24$ & $\mathrm{P} 2, \mathrm{P} 3 » 0.16$ \\
\hline $\mathrm{P} 1, \mathrm{P} 2, \mathrm{P} 3 » 0.6$ & $\mathrm{P} 2, \mathrm{P} 3 » 0.36$ & $\mathrm{P} 1, \mathrm{P} 2, \mathrm{P} 3 » 0.24$ \\
\hline \multicolumn{2}{|c|}{ Rumus } & Nilai \\
\hline Kombinasi Diagnosa & $(0.24+0.16+0.36) /(1-[])$ & 0.76 \\
\hline $\mathrm{P} 2, \mathrm{P} 3$ & $(0.24) /(1-[])$ & 0.24 \\
\hline $\mathrm{P} 1, \mathrm{P} 2, \mathrm{P} 3$ &
\end{tabular}

Tabel 8 Perhitungan

\begin{tabular}{|c|c|c|}
\hline \multicolumn{3}{|c|}{ Timbulnya Halusinasi (P2, P3) } \\
\hline$\#$ & $\mathrm{P} 1 » 0.1$ & $\emptyset » 0.9$ \\
\hline $\mathrm{P} 2, \mathrm{P} 3 » 0.76$ & $\mathrm{P} 2, \mathrm{P} 3 » 0.76$ & $\mathrm{P} 2, \mathrm{P} 3 » 0.684$ \\
\hline $\mathrm{P} 1, \mathrm{P} 2, \mathrm{P} 3 » 0.24$ & $\mathrm{P} 1 » 0.024$ & $\mathrm{P} 1, \mathrm{P} 2, \mathrm{P} 3 » 0.216$ \\
\hline \multicolumn{2}{|c|}{ Rumus } & Nilai \\
\hline Kombinasi Diagnosa & $(0.684) /(1-[0.076])$ & 0.7403 \\
\hline $\mathrm{P} 2, \mathrm{P} 3$ & $(0.024) /(1-[0.076])$ & 0.026 \\
\hline $\mathrm{P} 1$ & $(0.216) /(1-[0.076])$ & 0.2338 \\
\hline $\mathrm{P} 1, \mathrm{P} 2, \mathrm{P} 3$ & &
\end{tabular}

Keputusan:

Berdasarkan gejala yang terpilih maka diagnosa paling akurat adalah Parsial Primer, Parsial Sekunder dengan tingkat kepercayaan $\mathbf{7 4 \%}$.

\section{Implementasi Sistem}

Implementasi sistem merupakan proses penerapan implementasi Sistem Pakar Mendiagnosa Penyakit Epilepsi Di Rumah Sakit Sultan Sulaiman menggunakan metode Dempster Shafer. Berikut akan dijelaskan mengenai form-form yang terdapat dalam sistem yang telah dirancang untuk diimplementasikan.

\subsection{Form Login}

Form login merupakan halaman yang ditampilkan pertama kali pada saat sistem dijalankan oleh pengguna untuk masuk kedalam sistem. Disini pengguna akan memasukkan username dan password yang telah disediakan didalam database. Jika benar maka sistem akan menampilkan menu utama, sedangkan jika salah maka sistem akan menolak. Gambar form login dapat dilihat pada gambar 3 dibawah:

\subsection{Form Menu Utama}

\section{Gambar 3 Form Login}

Form utama merupakan halaman yang akan ditampilkan setelah pengguna berhasil melakukan login. Form Menu utama berisi halaman utama pada sistem dan menu-menu yang dapat digunakan oleh pihak pengguna. Gambar form utama dapat dilihat pada gambar dibawah 


\subsection{Form Penyakit}

Form ini digunakan oleh pengguna untuk menampilkan data penyakit berupa Nomor Penyakit, Kode Penyakit, Nama Penyakit, dan Keterangan. Kemudian pengguna dapat melakukan tambah, refresh, edit, hapus, dan cetak. Sistem akan memproses kedalam database yang telah disediakan. Gambar form Data Penyakit dapat dilihat pada gambar dibawah:

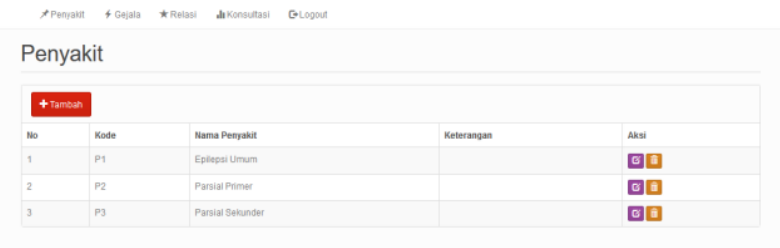

\section{Form Gejala}

Gambar 5 Form Penyakit

Form ini digunakan unutk menampilkan semua gejala yang ada berupa Kode Penyakit, Nama Gejala, dan Bobot. Form ini juga dapat melakukan pencarian, tambah, refresh, edit, hapus, dan cetak lalu akan menyimpan ke database yang disediakan. Gambar form Gejala dapat dilihat pada gambar dibawah:
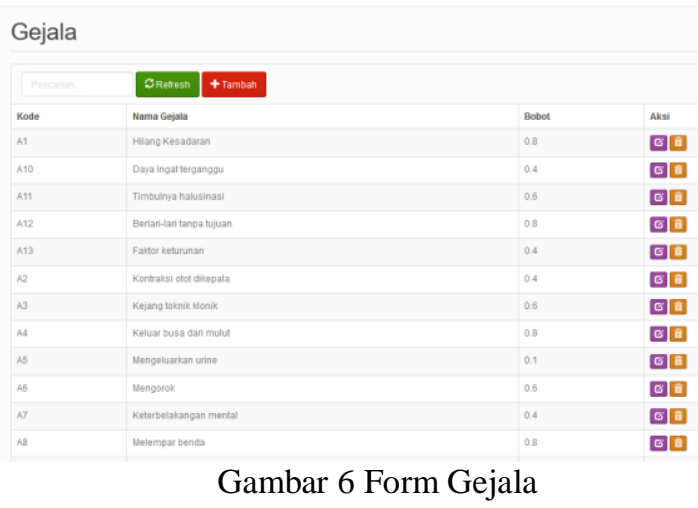

Gambar 6 Form Gejala 


\subsection{Form Keputusan}

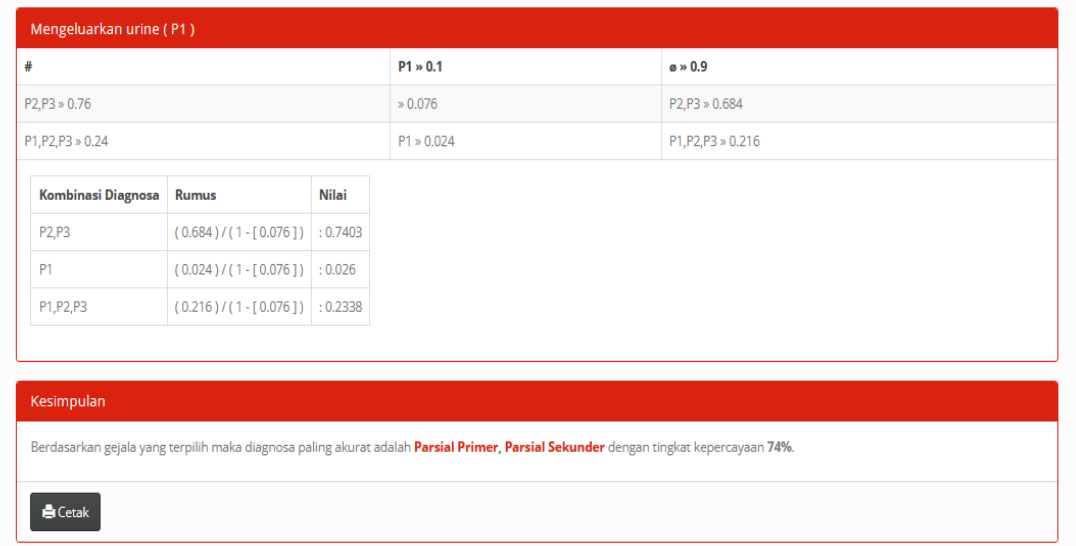

Gambar 7 Form Keputusan

\section{Kesimpulan}

Berdasarkan penelitian dan implementasi yang dilakukan pada "Sistem Pakar Mendiagnosa Penyakit

Epilepsi Menggunakan Metode Dempster Shafer", maka dapat diambil kesimpulan sebagai berikut:

1. Sistem pakar mendiagnosa penyakit epilepsi menggunakan metode dempster shafer dapat memberikan keputusan dari hasil penyakit epilepsi umum sebesar 99\% tingkat akurasi kepercayaan, dan untuk gajala penyakit secara acak didapatkan diagnosa paling akurat yaitu gabungan parsial primer dan parsial sekunder dengan akurasi tingkat kepercayaan $74 \%$.

2. Penelitian ini dapat memberikan reverensi bagi pihak Rumah Sakit Sultan Sulaiman dalam menentukan penyekit epilepsi secara komputerisasi.

3. Metode Dempster Shafer cukup efektif dalam memberikan secara akurat.

6. Saran

Penelitian ini memberikan saran untuk pengembangan penelitian dimasa mendatang, yaitu:

1. Untuk penelitian selanjutnya diharapkan menggunakan beberapa algoritma untuk mendapatkan beberapa akurasi yang lebih tinggi.

2. Untuk pengembangan sistem selanjutnya agar sistem dapat diakses secara online

3. Diharapkan untuk penelitian lebih lanjut agar menggunakan gejala yang lebih banyak lagi.

\section{Daftar Pustaka}

[1] A. Subana and R. F. Siahaan, "Sistem Pakar Mendiagnosis Penyakit Pada Ayam Broiler Menggunakan Metode Teorema Bayes Berbasis Web," J. Nas. Komputasi dan Teknol. Inf., vol. 4, no. 2, 2021.

[2] A. Suprianto and A. A. F. Matsea, "Rancang Bangun Aplikasi Pendaftaran Pasien Online Dan Pemeriksaan Dokter Di Klinik Pengobatan Berbasis Web," J. Rekayasa Inf., vol. 7, no. 1, pp. 48-58, 2018.

[3] P. Studi Sistem Informasi and S. Triguna Dharma, "SISTEM PAKAR UNTUK MENDIAGNOSA PENYAKIT ANEMIA DENGAN MENGGUNAKAN METODE TEOREMA BAYES * Trinanda Syahputra \#1, Muhammad Dahria \#2 , Prilla Desila Putri \#3," Saintikom, vol. 16, no. 3, pp. 284-294, 2017.

[4] M. Arifin, S. Slamin, and W. E. Y. Retnani, "Penerapan Metode Certainty Factor Untuk Sistem Pakar Diagnosis Hama Dan Penyakit Pada Tanaman Tembakau,” Berk. Sainstek, vol. 5, no. 1, p. 21, 2017.

[5] Kusrini, "Penggunaan Certainty Factor dalam Sistem Pakar untuk Melakukan Diagnosis dan Memberikan Terapi Penyakit Epilepsi dan Keluarganya," 2013.

[6] A. E. Budianto and S. Kom, "Aplikasi Sistem Pakar Menggunakan Metode Backward Chaining Untuk Analisis Penyakit Hewan Ternak," vol. 1, no. 1, pp. 33-35, 2015.

[7] C. Simanjuntak and F. Riandari, "Sistem Pakar Mendiagnosa Penyakit Keputihan Pada Wanita Dengan Metode Teorema Bayes," J. Nas. Komputasi dan Teknol. Inf., vol. 4, no. 2, 2021.

[8] J. E. Hutagalung and J. Hutahaean, "Sistem Pakar Dengan Metode Backward Chaining Untuk Pengujian Transistor Di Laboratorium Elektronika," Riau J. Comput. Sci., vol. 1, no. 1, pp. 9-15, 2015.

[9] E. I. Anna and M. B. Hartanto, "Sistem Pakar Untuk Diagnosis Penyakit Ayam Dengan Menggunakan 
Metode Certainty Factor ( CF ) Berbasis Web Teknologi ilmu komputer telah berkembang pesat, hal ini di tandai dengan memecahkan berbagai permasalahan, Semakin cerdas sistem itu dan semakin pe," vol. 2, no. 1, pp. 1-13, 2021.

[10] M. Munawir, S. Susmanto, Z. Zulfan, and T. Hidayat, "Perancangan Aplikasi Pengelolaan Surat pada Dinas Kependudukan Catatan Sipil Kabupaten Aceh Besar,” J. Serambi Eng., vol. 5, no. 3, 2020.

[11] M. Munawir, S. Susmanto, Z. Zulfan, and Y. Yanti, "Sistem Pelayanan Surat Administrasi Masyarakat Gampong Berbasis Webbase dengan menggunakan Framework CodeIgniter,” J. Serambi Eng., vol. 5, no. $1,2020$.

[12] J. Teknik, “Journal of Information Technology and Accounting Vol. III, No. 1, Januari 2020," vol. III, no. 1, pp. 9-20, 2020. 